\title{
A Theoretical Analysis of Digital Marketing Adoption by Startups
}

\author{
Sérgio Teixeira ${ }^{1}$, José Martins ${ }^{1,2}$, Frederico Branco ${ }^{1,2}$, \\ Ramiro Gonçalves ${ }^{1,2}$, Manuel Au-Yong-Oliveira ${ }^{3}$ and Fernando Moreira ${ }^{4}$ \\ ${ }^{1}$ University of Trás-os-Montes e Alto Douro \\ 5000-801 Vila Real, Portugal \\ sergioteixeira13@hotmail.com \\ ${ }^{2}$ University of Trás-os-Montes e Alto Douro \\ 5000-801 Vila Real, Portugal \\ INESC TEC (coordinated by INESC Porto), Faculty of Engineering, University of Porto \\ 4200-465 Porto, Portugal \\ \{fbranco,jmartins, ramiro\}@utad.pt \\ ${ }^{3}$ GOVCOPP, Department of Economics, Management, Industrial Engineering and Tourism \\ University of Aveiro \\ 3810-193 Aveiro, Portugal \\ mao@ua.pt \\ ${ }^{4}$ Univ Portucalense, Portucalense Institute for Legal Research - IJP \\ Research on Economics, Management and Information Technologies - REMIT \\ Porto \& Universidade Aveiro, IEETA \\ Aveiro, Portugal \\ fmoreira@uportu.pt
}

\begin{abstract}
With the rapid growth in the use of digital platforms for the dissemination and expansion of a company's business reach, it is vitally important that startup firms are firmly aware of the options when deciding whether to adopt a particular technology because they often have low resource availability, which reduces their margin for error. In order to help these companies to adopt Digital Marketing in a more secure way by knowing the most relevant factors that they can find as concerns the adoption of technologies, this study will analyze the factors that influence the adoption of technology, identifying them initially through the systematic literature review of similar scientific works.
\end{abstract}

Keywords: Digital Marketing; Startups; IT Adoption; Literature Review.

\section{Introduction}

Nowadays it is mandatory for companies to have an online presence, either through an institutional website or an online store, with the ultimate goal of expanding the market associated with the sale of a product or service offered by that company. In order to make the most of this online business method, a set of techniques have been 
developed to bring end users to these digital platforms, in order to trigger their purchase behaviour. These techniques, typically associated with the "digital marketing" concept, have main functions such as the analysis, planning, implementation and control of projects aimed at satisfying consumers' demand, wishes and needs, with quality, hence bringing profit to the company. Thus, digital marketing is considered to play an important role in the survival, development, and success of small and new ventures.

As digital marketing is highly correlated with new information technologies, it is expected that traditional marketing techniques and characteristics will not only serve as a basis but also will be greatly developed, in order to improve the overall business performance. Nevertheless, this principle applies mainly to new and small businesses that rely heavily on new customers and new investors in their products and services.

Considering the widespread set of perspectives on the adoption of digital marketing at the organizational level, the present work aims at identifying the most relevant determinants for the adoption of digital marketing by Portuguese startups. This output will serve, from our perspective, as the basis for future research on the topic.

\section{Theoretical Framework}

\subsection{Digital Marketing Conceptualization}

The Internet, as well as other digital technologies, played a crucial role in the progress and evolution of marketing. It allowed the existence of a wide range of products, services, means of purchase, prices, and new modes of communication that make information more quickly available to consumers. The Internet has showed companies a novel way to reach new markets, as well as having provided the opportunity to offer new products and services, using online communication techniques, placing them in the same market of larger companies when used appropriately and corresponding to the requirements of the sector concerned.

In summary, marketing functions involve the analysis, planning, implementation and control of projects designed to achieve and satisfy demand, whether with products or services, considering the desires and needs of the consumers/users, with quality and in order to make a profit for the company. Marketing is considered to be of utmost relevance in the survival, development, and success of small and new ventures. Marketing is now using technology to innovate and to enable firms to be inserted in expanding markets in numerous forms. The companies that use these new technologies will have different perspectives and objectives with their use, and it should be noted that the learning stage of digital marketing may result in a slow process [1].

According to Levitt [2] marketing "is the process of attracting the customer". In a similar note, Kotler [3] argues that marketing "is the social and management process through which individuals and groups obtain what they need and desire through the creation and exchange of products and values". A similar perspective is presented by 
Skacel [4], according to whom, "it is what we do to get more consumers to use more services or buy more products, to meet more needs and more often".

\subsection{Importance and Benefits of Digital Marketing}

In sum, the functions of marketing involve the analysis, planning, implementation and control of projects designed to achieve and satisfy demand, whether with products or services, considering the desires and needs of consumers / users, with quality and in a way to bring profit to the company. Marketing is considered to be extremely relevant in the survival, development, and success of small and new ventures.

According to Chaffey, Ellis-Chadwick, Mayer and Johnston [5], associated to digital marketing are several tangible and intangible benefits. The authors consider tangible benefits to increase sales of new sales opportunities resulting in increased revenue from new customers, new markets, and existing customers (repeat sales or cross selling); cost reduction due to reduced time for customer service, online sales and reduced costs of printing and distribution of marketing communications. With respect to intangible benefits, these are presented as the communication of corporate image; enhancement/improvement of the brand; marketing communications now faster and more responsive (including public relations); improved customer service; improved learning for the future; the meeting of customers' expectations for having a website; identifying of new partners and better support for existing partners; better management of marketing information and information about the customer; more customer feedback on products.

Marketing is very important for the creation of companies, especially as they face environmental challenges, such as the rapid evolution of technology, globalization and increasingly more sophisticated competitors. As such, they need to be able to identify and pursue market opportunities, adapting to a dynamic environment, despite the limited financial and human resources that they possess [6] and the set-back of a limited market and small customer base [7]. The main tool to take advantage of these opportunities, currently, is clearly the Internet - where companies promote their products/services to a global target audience, reaching large masses at a greatly reduced cost. For this reason it is mandatory to give maximum attention to digital marketing to obtain the maximum competitive advantage that this medium provides to companies. Marketing professionals are required to constantly update their knowledge and to constantly search for information, because this sector is always undergoing constant change.

\subsection{Digital Marketing in Startups}

In the case of an SME (Small and Medium-sized Enterprise), the distinction between marketing and sales becomes very tenuous, since marketing in SMEs takes place during the sales process [8]. What causes that is the fact that many managers of SMEs have a wrong perception of what the sale is for Marketing [9], however it is undenaible that marketing exists to increase sales. [10] performed some tests taking as main actors the entrepreneurs themselves and what marketing means to them. As you 
would expect, the conclusion which was reached was that entrepreneurs have an incomplete meaning and perception of what marketing is. The majority considered marketing to be synonymous with sales or advertising, thereby emphasizing shortterm goals, rather than long term profitability. Managers should see marketing as a tool for strategic planning or strategic orientation, however the vast majority of them seemed to opt for a product and sales orientation [10].

Flexibility is a key word for marketing in SMEs, since marketing is bound to evolve throughout the life cycle of the company, to better position the product in the market, and in order to satisfy the needs of customers. The flexibility and reduced response time SMEs manage in practice are a competitive advantage compared with large enterprises [9, 11-13]. SMEs practice creative marketing, of an alternative and instinctual nature even given weak financial resources. Typically, the success of innovation in SMEs is determined by the novelty, the power of new adoptions that translate into a growing number of opportunities for growth.

\section{Digital Marketing Adoption}

\subsection{Web-Based Information Technology Adoption}

There are several studies on the use of models to characterize the adoption and use of new technologies at the enterprise level. These models enable researchers to have an idea of the major determinants that must be taken into account as potential influencers in the process of incorporating the referred technologies. As argued by Karahanna, Straub and Chervany [14], these models offer valid arguments that allow managers, users, as well as the academic community, to gain a better perception of the application and potential of new technologies, with the purpose of leading to more productive modes of operation.

As digital marketing is a recent concept, especially when perceiving its application to SMEs (that have reduced resources and cannot make risky investments), there is an increasing demand for studies focusing on the adoption of the referred technology by small and resource-limited companies, in order to reach a full understanding on what might be the obstacles and determinants of the adoption process.

In order to perform a valid analysis of the existing scientific literature, a set of international scientific repositories, such as the ACM Digital Library, the IEEE Xplore Digital Library, the Web of Science, ScienceDirect, SCOPUS and Google Scholar, have all been used as the source for literature that focuses upon the adoption of web-based technologies, such as digital marketing, at the firm level.

An initial analysis of the existing literature allowed us to perceive that the majority of the existing research was drawn from more "traditional" IT adoption models, such as Rogers [15] theory on the Diffusion of Innovation (DOI), Davis, Bagozzi and Warshaw [16] technology-organization-environment framework (TOE) and, also, from the merging of these models with other existing models, such as the Institutional Theory and Iacovou, Benbasat and Dexter [17] IT adoption model. 
When assessing the existing literature, we were able to identify 41 articles that directly addressed the adoption of web-based information technologies at the firm level. A direct analysis allowed to perceive that since 2014 the topic has been directly approached a number of times (Figure 1).

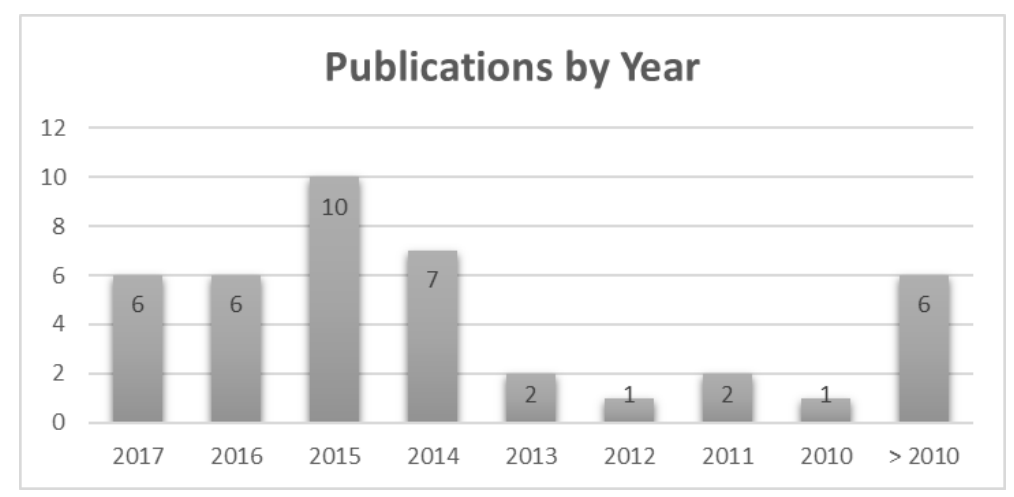

Fig. 1. Evolution of the number of publications that directly addressed the adoption of webbased information technologies at the firm level.

\subsection{Digital Marketing Adoption Determinants}

The adoption of digital marketing by startups is of vital importance since this technology might represent a communication tool that can be used at a small cost and with lower risk. However, any decision is not without error, hence the need to understand the variables that may influence, directly or indirectly, the referred technology adoption.

We analyzed 72 articles, on which we performed an initial filtering based on their keywords, title, methodological approach and contribution. Of this initial set, only a sub-set of 41 articles were considered relevant to our research.

Through a detailed analysis of the referred articles, we were able to identify 45 variables associated with the adoption of digital marketing by organizations. In Table 1 it is possible to view the referred variables, in descending order of the number of occurrences in the literature [11, 18-57].

A brief description of the identified variables, with the biggest number of usages in the literature, is presented below:

- Ease of Use/Complexity: The degree to which an innovation is perceived as easy to use and understand. New technologies that are simpler to understand are adopted faster than others which require more learning time.

- Perceived Benefits: Degree to which a company can take advantage of using a certain technology. Measured by the gains or improvements derived from the use of the technology, such as the recruiting of new clients, or the improved feedback provided by the customer base. 
- Cost: This factor is also often taken into account for the implementation of new technologies. Relevant factors are how much cheaper a technology is as well as how much more easily and quickly it is implemented.

- Perceived Industry Pressure: This factor is connected to the enterprise's obligation to evolve to be able to maintain / increase its market power. This takes into account the entry of new operators, the threat of substitute products and services, the bargaining power of customers, as well as the power of suppliers of resources and the intensity of rivalry.

- Expectable Performance: The degree to which an organization believes that the use of a given technology will help the organization to achieve performance gains. The performance at the level of the organization can be translated in terms of business efficiency, performance in sales, customer satisfaction and the development of a relationship with the client.

- External Pressure: External pressures encompasses several factors present in the environment of the organization. These include competitors' actions, market conditions and legal regulations.

- Compatibility: The degree to which a given technology is compatible with the existing business processes, practices and systems, as some technologies may require significant change.

- Government Pressure: The level of pressure imposed by government entities through regulations and mandatory procedures.

- Readiness: The quantity and quality of existing (human, technical and financial) resources held by an organization that assure the capability to be ready to adopt a given technology.

- Size: Refers to the dimension of the organization both in terms of the number of existing employees and its business volume.

- Business Dependence on IT: Degree of readiness that a company has to assign the implementation of new technology to IT professionals and the measurement of the maintenance of the technology base.

- Availability/Manager Attributes: Degree of ease that the person responsible for the project will have to accept the implementation of new technology.

- Customer Power/Pressure: Degree of demand on the part of an important customer for the company to implement a certain technology. This type of pressure has a major role in encouraging companies to adopt a technology. An innovative customer could force the organization to use and adopt a new innovation.

- Social Influences: Degree to which an organization believes that through someone influential it is important to use a certain technology.

- Trustworthiness: Degree of trust that a company can expect for the implementation and use of the new technology in their business. 
Table 2. Adoption determinants identified in the analysed literature.

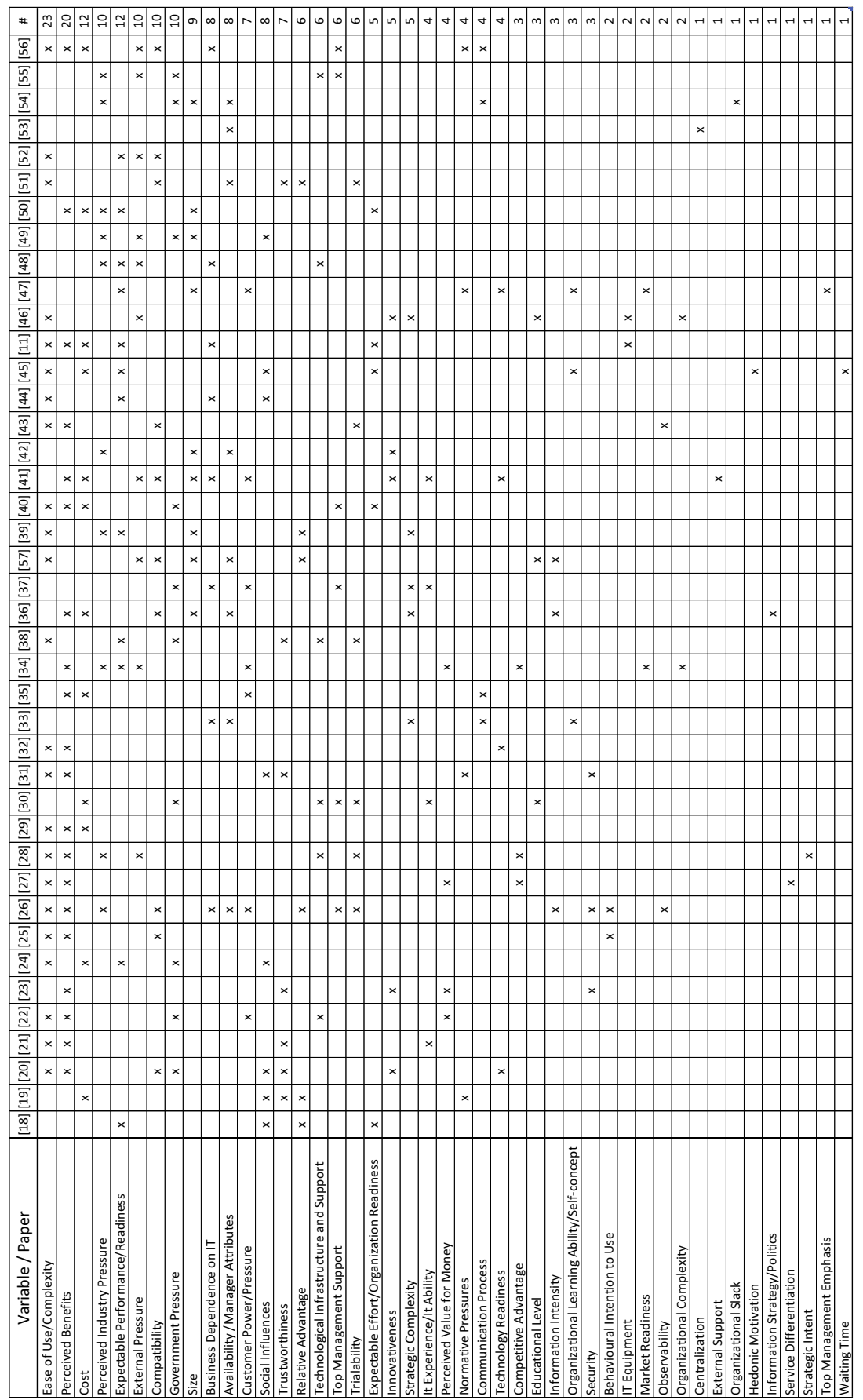


- Relative Advantage: The degree to which an innovation can bring benefits to an organization. Firms must have a vision that defines the benefits that will be gained by the performance of a certain technology and affecting the performance, exponential growth, financial growth and competitive advantages of the company.

- Technological Infrastructure and Support: Degree to which an organization believes that an organizational infrastructure and technology exists to give support to the system.

- Top Management Support: A large literature on organizational innovation suggests that management support is considered one of the most important factors that influence the adoption of innovation. The successful adoption of innovation requires the support of top management to integrate innovation in business as well as in other processes.

- Trialability: Degree to which an innovation can be experienced for a limited time.

- Expectable Effort/Organizational Readiness: Degree of ease of learning and of implementation of the technology.

- Innovativeness: Ability of a company to be open to new ideas and use of new solutions for its projects.

- Strategic Complexity: Degree of difficulty that a company has to define a good strategic plan to take part in a certain technology. The literature on marketing stresses the importance of strategic guidance to help companies build dynamic capabilities in environments of permanent change.

\section{Results Analysis}

The study allowed for the collection of a set of determinants considered critical to the adoption of digital marketing at the firm level. We were also able to acknowledge that the majority of the considered literature is drawn from traditional information technology adoption models.

During the present study, a set of 45 variables was identified as being associated to the adoption of digital marketing, of which we have selected 21 , considering that these were the ones with the most representativity in the analysed literature.

Based on the results achieved it is possible to perceive that digital marketing is a vital technology for the development, sustainability and increase in performance of organizations. However, its adoption by new and small firms, such as startups, might be a complex process considering the number of determinants that should be addressed in order for the adoption process to be successful.

From the literature analysis undertaken it was also possible to perceive the existence of limited knowledge on the adoption of digital marketing at the firm level, the difficulties (highlighted by firms) in recruiting and training skilled professionals to enhance the results due to the adoption of digital marketing, and the existing decrease of the price associated with outsourcing digital marketing services that, when strategically used in aligned marketing strategies, tend to produce very positive results. 


\section{Final Considerations}

\subsection{Theoretical and Practical Implications}

The present research seeks to fill a knowledge gap concerning the characterization of the digital marketing adoption process at the firm level, with a particular focus on the adoption of the referred technology by startups. During our research we were able to identify several studies focused on the adoption of similar technologies, such as ecommerce and cloud computing, that can be used as similar studies to the one we were performing herein and whose results can also be analysed and taken into consideration.

With the above in mind, the present research aims to contribute, in a positive manner, to both the development of existing knowledge on the adoption of digital marketing by startups, and to a more effective adoption of the referred technology, digital marketing, by the same set of organizations, through the identification of the determinants with the most relevancy to the adoption process.

\subsection{Conclusions and Future Work}

The performed literature analysis allowed us to acknowledge that the adoption of digital marketing at the firm level is a very up-to-date topic and its application to new and small enterprises, such as startups, needs to be analysed in a more detailed manner considering the lack of literature focusing on this topic.

As concerns future work, we will be performing a focus group interaction, comprising a group of ten experts, aimed at assessing their considerations on the variables identified as the ones with the most relevancy to the digital marketing adoption process at the firm level. To do this, the list of variables, identified in the present study, will be put up for discussion within the group of experts, hence aiming on filtering the sub-set of variables considered as the most relevant to the previously mentioned technology adoption process.

\section{References}

1. Hall, B.H., Khan, B.: Adoption of new technology. National bureau of economic research (2003)

2. Levitt, T.: Marketing myopia. Harvard business review 38, 24-47 (1960)

3. Kotler, P.: Reinventing marketing to manage the environmental imperative. Journal of Marketing 75, 132-135 (2011)

4. Skacel, R.K.: The marketing plan: how to prepare it, what should be in it. NTC Business Books (1990)

5. Chaffey, D., Ellis-Chadwick, F., Mayer, R., Johnston, K.: Internet marketing: strategy, implementation and practice. Pearson Education (2009) 
6. Aldrich, H., Auster, E.R.: Even dwarfs started small: Liabilities ofage and size and their strategic implications. Research in organizational behavior 8, 165-186 (1986)

7. Carson, D.J.: The evolution of marketing in small firms. European Journal of Marketing 19, 7-16 (1985)

8. Oakey, R.: Innovation and the management of marketing in high technology small firms. Journal of Marketing Management 7, 343-356 (1991)

9. Mc Cartan-Quinn, D., Carson, D.: Issues which impact upon marketing in the small firm. Small business economics 21, 201-213 (2003)

10. Alberto, M., Gianluigi, G., Peluso, A.: What is marketing for SME entrepreneurs? The need to market the marketing approach. Journal of Marketing Trends-Small \& Medium Enterprises, I 67-74 (2010)

11. Gilmore, A., Gallagher, D., Henry, S.: E-marketing and SMEs: operational lessons for the future. European Business Review 19, 234-247 (2007)

12. Carson, D., Gilmore, A., Perry, C., Gronhaug, K.: Qualitative marketing research. Sage (2001)

13. Heathfield, P.: SME business leaders need powerful on-board computers. Industrial Management \& Data Systems 97, 233-235 (1997)

14. Karahanna, E., Straub, D.W., Chervany, N.L.: Information technology adoption across time: a cross-sectional comparison of pre-adoption and post-adoption beliefs. MIS quarterly 183-213 (1999)

15. Rogers, E.M.: Diffusion of Innovations: modifications of a model for telecommunications. Die Diffusion von Innovationen in der Telekommunikation, pp. 25-38. Springer (1995)

16. Davis, F.D., Bagozzi, R.P., Warshaw, P.R.: User acceptance of computer technology: a comparison of two theoretical models. Management science 35, 982-1003 (1989)

17. Iacovou, C.L., Benbasat, I., Dexter, A.S.: Electronic data interchange and small organizations: Adoption and impact of technology. MIS quarterly 465-485 (1995)

18. Goswami, A., Dutta, S.: E-Commerce Adoption by Women Entrepreneurs in India: An Application of the UTAUT Model. Business and Economic Research 6, 440-454 (2017)

19. Wu, K., Vassileva, J., Zhao, Y.: Understanding users' intention to switch personal cloud storage services: Evidence from the Chinese market. Computers in Human Behavior 68, 300-314 (2017)

20. Kumar, R., Sachan, A.: Empirical Study to Find Factors Influencing e-Filing Adoption in India. In: Proceedings of the Special Collection on eGovernment Innovations in India, pp. 52-57. ACM, (Year)

21. Sun, E., McLachlan, R., Naaman, M., Tech, C.: TAMIES: A Study and Model of Adoption in P2P Resource Sharing and Indirect Exchange Systems. In: CSCW, pp. 2385-2396. (Year)

22. Hasan, M.R., Lowe, B., Petrovici, D.: Antecedents of Adoption of Pro-poor Innovations in the Bottom of Pyramid: An Empirical Comparison of Key Innovation Adoption ModelsAn Abstract. Marketing at the Confluence between Entertainment and Analytics, pp. 10811082. Springer (2017)

23. Kim, Y., Park, Y., Choi, J.: A study on the adoption of IoT smart home service: using Value-based Adoption Model. Total Quality Management \& Business Excellence 1-17 (2017)

24. Engotoit, B., Moya, M.B., Mayoka, K.G., Bonface, A.: A Mobile-Based Communication Adoption Model for agricultural market information dissemination in Uganda. Global Journal of Computers \& Technology Vol 5, (2016)

25. Kanchanatanee, K., Suwanno, N., Jarernvongrayab, A.: Factors Affecting the Intention to use E-marketing of Small and Medium Sized Businesses in the Three Southern Border Provinces of Thailand. International Journal of Business and Social Science 5, (2014)

26. Iqbal, T., El-Gohary, E.: An attempt to understand e-marketing: an information technology prospective. International Journal of Business and Social Science 5, (2014) 
27. Abubakar, S., Ahmad, A., Umar, M.a.: E-Marketing Adoption and Competitive Advantage: Study of Commecial Banks in Nigeria. I S E R 27th INTERNATIONAL CONFERENCE, pp. 1-6. ISER, Riyadh, Saudi Arabia (2016)

28. Iddris, F., Ibrahim, M.: Examining the relationships between e-marketing adoption and marketing performance of small and medium enterprises in Ghana. Journal of Marketing and Consumer Research 10, 160-169 (2015)

29. Mochoge, O.C.: SMEs Adoption of Web-based Marketing: Empirical Evidence from Kenya. IJCSI International Journal of Computer Sciences2014 11, 2 (2014)

30. Kazungu, I., Panga, F.P., Mchopa, A.: IMPEDIMENTS TO ADOPTION OF EMARKETING BY TANZANIAN SMALL AND MEDIUM SIZED ENTERPRISES: AN EXPLANATORY MODEL.

31. SHOTER, A.M., BATAINEH, A.Q., SALHAB, H.A.: Building a Model for Determining the Factors Affecting Mobile Marketing Acceptance and Adoption. IRMBR - International Review of Management and Business Research 5, 22 (2016)

32. BAŞGÖZE, P.: Integration Of Technology Readiness (Tr) Into The Technology Acceptance Model (Tam) For M-Shopping. International Journal of Scientific Research and Innovative Technology 2, 26-35 (2015)

33. Musa, H., Li, S.C.H., Abas, Z.A., Mohamad, N.: Adoption Factor of Mobile Marketing: The Case of Small Medium Enterprises (SMEs) in Malaysia. International Review of Management and Marketing 6, (2016)

34. Kithinji, L.W.: Internet marketing and performance of small and medium enterprises in Nairobi county. University of Nairobi (2014)

35. Mokhtar, N.F.: Internet Marketing Adoption by Small Business Enterprises in Malaysia. International Journal of Business and Social Science 6, (2015)

36. Herzallah, F., Mukhtar, M.: Organization Information Ecology and E-Commerce Adoption: Effect on Organizational SMEs Performance. Journal of Computer Science 11, 540 (2015)

37. Al-Somali, S.A., Gholami, R., Clegg, B.: Determinants of B2B e-commerce adoption in Saudi Arabian firms. International Journal of Digital Society (IJDS) 2, 406-415 (2011)

38. Albesher, A.A., De Coster, R.: The impact of IT resources on SMEs innovation performance.

39. White, G.R., Afolayan, A., Plant, E.: Challenges to the adoption of e-commerce technology for supply chain management in a developing economy: a focus on Nigerian SMEs. Ecommerce Platform Acceptance, pp. 23-39. Springer (2014)

40. Al-Alawi, A., Al-Ali, F.: Factors affecting e-commerce adoption in SMEs in the GCC: An empirical study of Kuwait. Research Journal of Information Technology 7, 1-21 (2015)

41. Rahayu, R., Day, J.: Determinant factors of e-commerce adoption by SMEs in developing country: evidence from Indonesia. Procedia-Social and Behavioral Sciences 195, 142-150 (2015)

42. Wamba, S.F., Carter, L.: Social media tools adoption and use by SMEs: An empirical study. Social Media and Networking: Concepts, Methodologies, Tools, and Applications, pp. 791-806. IGI Global (2016)

43. Ndekwa, A.G.: Drivers of electronic commerce (e-commerce) among small and medium tourist enterprises (SMTEs) in Tanzania. International Journal of Science and Research (IJSR) 4, 2512-2517 (2014)

44. Fortes, N., Pereira, J.H., Costa, J.F.d.: The adoption of cloud computing services by Portuguese companies: The impact of marketing efforts. RISTI-Revista Ibérica de Sistemas e Tecnologias de Informação 33-48 (2016)

45. Dwivedi, Y.K., Shareef, M.A., Simintiras, A.C., Lal, B., Weerakkody, V.: A generalised adoption model for services: A cross-country comparison of mobile health (m-health). Government Information Quarterly 33, 174-187 (2016) 
46. Vilaseca, J., Torrent, J., Meseguer, A., Rodríguez-Ardura, I.: An integrated model of the adoption and extent of e-commerce in firms. International Advances in Economic Research 13, 222-241 (2007)

47. Wu, F., Mahajan, V., Balasubramanian, S.: An analysis of e-business adoption and its impact on business performance. Journal of the Academy of Marketing science 31, 425-447 (2003)

48. Brodie, R.J., Winklhofer, H., Coviello, N.E., Johnston, W.J.: Is e-marketing coming of age? An examination of the penetration of e-marketing and firm performance. Journal of interactive marketing 21, 2-21 (2007)

49. Tsiotsou, R.H., Vlachopoulou, M.: Understanding the effects of market orientation and emarketing on service performance. Marketing Intelligence \& Planning 29, 141-155 (2011)

50. Braun, P.: Networking tourism SMEs: e-commerce and e-marketing issues in regional Australia. Information Technology \& Tourism 5, 13-23 (2002)

51. Tanakinjal, G.H., Deans, K.R., Gray, B.J.: Third screen communication and the adoption of mobile marketing: A Malaysia perspective. International Journal of Marketing Studies 2, 36 (2010)

52. Dlodlo, N., Dhurup, M.: Drivers of e-marketing adoption among small and medium enterprises (SMEs) and variations with age of business owners. Mediterranean Journal of Social Sciences 4, 53 (2013)

53. Alford, P., Page, S.J.: Marketing technology for adoption by small business. The Service Industries Journal 35, 655-669 (2015)

54. Dahnil, M.I., Marzuki, K.M., Langgat, J., Fabeil, N.F.: Factors influencing SMEs adoption of social media marketing. Procedia-social and behavioral sciences 148, 119-126 (2014)

55. Fazli, S., Shirdastian, H., Laroche, M.: Effective factors of successful cloud marketing adoption by SMEs: the case of Iran. International Journal of Business Environment 7, 415$434(2015)$

56. Maduku, D.K., Mpinganjira, M., Duh, H.: Understanding mobile marketing adoption intention by South African SMEs: A multi-perspective framework. International Journal of Information Management 36, 711-723 (2016)

57. Almoawi, A., Mahmood, R.: Applying the OTE model in determining the e-commerce adoption on SMEs in Saudi Arabia. Asian Journal of Business and Management Sciences 1, 12-24 (2011) 